\title{
Investigation of the Effect of the Use of Bamboo and Silver Yarn on Antibacterial Activity in Towel Fabric
}

\author{
Navruz PAKSOY ${ }^{1}$ (D) 0000-0002-0741-1174 \\ Seval KONUKOĞLU² (D) 0000-0001-6171-1883 \\ Levent Güven AYAR ${ }^{2}$ (D) 0000-0001-8917-6157 \\ Cansu BATCIK ${ }^{2}$ (D) 0000-0002-1400-5852 \\ Hüseyin AYDIN ${ }^{1}$ (D) 0000-0003-3593-8712
}

${ }^{1}$ Sanko Textile Enterprises Industry and Trade Corporation (Towel) R\&D Center, Gaziantep/Türkiye

${ }^{2}$ Sanko Textile Enterprises Industry and Trade Corporation (Yarn) R\&D Center, Gaziantep/Türkiye

Corresponding Author: Navruz Paksoy, nevruzpaksoy_@hotmail.com

\begin{abstract}
Towel fabrics provide a suitable environment for bacterial growth due to the moisture on them. For this reason, studies are carried out on the antibacterial properties of the towel. In this study, it is aimed to conduct research activities within the scope of developing antibacterial terry fabric. For this purpose, different terry fabric productions were made using silver yarn, bamboo and antibacterial chemicals, and their antibacterial properties were examined. In this context, the antibacterial chemical finishing process, known as the classical method, was applied to the towels, which were first woven from $100 \%$ cotton yarn. In addition, towel fabrics were produced by using $70 \%$ bamboo-30\% cotton yarn and $92 \%$ cotton-8\% silver yarn. Antibacterial activities of the obtained fabric samples against $S$. aureus and K. pneumonie bacteria according to AATCC 100 standard were examined.
\end{abstract}

\author{
ARTICLE HISTORY \\ Received: 15.12 .2020 \\ Accepted: 01.09.2021
}

\section{KEYWORDS}

Antibacterial property, bamboo, silver thread, antibacterial finish, towel

\section{INTRODUCTION}

Microorganisms are too small to be seen with the naked eye. This structure includes bacteria, fungi, algae and viruses. Textile materials carry microorganisms as bacteria and fungi due to the adhesion of these organisms to their surfaces. These microorganisms are found almost everywhere in the environment and multiply rapidly when they encounter moisture and temperature. The proliferation of microorganisms on the textile during use and storage both negatively affects the textile product and causes health problems for the user [1-4].

Natural fibers such as cotton are more susceptible to microorganism related problems than synthetic fibers due to their porous and hydrophilic structure. Cellulosic fibers, which are widely used in the textile industry due to these properties, provide a suitable environment for microorganisms. Textiles tend to harbor micro-organisms responsible for proliferation of diseases, unpleasant odors, discoloration and deterioration of fabrics. The most common active ingredients used in antimicrobial applications are triclosan, quaternary ammonium salts and metals (silver, copper, zinc, etc.). Human and environmental health, process-related concerns have especially increased interest in silver-doped antimicrobial materials. Although many metals are known to have antimicrobial effects, silver is more preferred than other metals. The main reasons for this are that it is the most resistant metal against bacteria, it has been known for a long time that it does not have harmful effects on the body in its controlled use, it is cheaper to make it into a final product compared to most materials, and the easy production process $[2,5-9,10,11]$.

Silver compounds with a pronounced antibacterial effect against most pathogenic microorganisms are widely used 
[12]. Silver, on the other hand, is a relatively non-toxic disinfectant that can significantly reduce many types of bacteria and fungi. At the same time, the powerful antimicrobial activity of silver is known to be effective against nearly 650 types of bacteria. Silver is generally applied to textiles in colloidal form and nano metallic form or in insoluble silver salt dispersion. In the case of synthetic fibers, silver can be incorporated into a spinning solution in the form of a zeolite complex or nanoparticles. Silver nanoparticles show good antibacterial properties due to their large surface area $[9,11]$. Silver is used safely in many areas of textile [13].

Towel fabric is one of the main consumer products used by people around the world. Bathroom, sports, swimming pool, kitchen, beach, etc. towels with different water absorption properties are used in various places [14]. Terry fabrics consist of ground warp, pile warp and weft yarns $[14,15]$. Cotton fiber has been used in towel production for many years. Today, however; It is observed that bamboo fiber, which is claimed to have soft, anti-bacterial, high level of absorbency and high level of washing fastness, is preferred as much as cotton fiber in towel production [16]. Because bamboo contains bamboo extract, a substance called Bamboo Kun, it is difficult for disease-causing organisms or insects to affect this plant. This is why bamboo is grown naturally without pesticides. Bamboo fiber is an environmentally friendly fiber. Bamboo fiber is a type of regenerated cellulose fiber produced from the raw materials of bamboo pulp. The fineness and whiteness of bamboo fiber is similar to classic viscose [17-20]. Tusief et al. [21] reported that the use of bamboo fiber has a significant effect on its antibacterial activity feature.

Many studies have shown that textile materials made of antimicrobial fibers show longer durability against microorganisms. However, the applications made with the finishing chemical on the finished product also have various advantages such as ease of application [5, 22]. Perelshtein et al. conducted an antibacterial activity study by coating silver nanoparticles on different fabric types in their study. The Ag-fabric composite has been shown to show excellent antibacterial activity against Escherichia coli (gram-negative) and Staphylococcus aureus (grampositive) cultures [23].

Antibacterial towel feature is provided with finishing chemicals as a classical method. Antibacterial feature can also be achieved with fiber. The natural structure of bamboo fiber shows antibacterial properties. Silver fiber is also known as the fiber that provides another antibacterial property. While bamboo fiber from these fibers is used in the production of terry cloth, silver fiber was not used in the production of terry cloth in the literature screenings. Within the scope of the study, it was aimed to investigate the antibacterial properties of terry fabric by using bamboo and silver fiber, which are antibacterial fibers, in addition to the antibacterial chemical finishing process. In this direction, as an alternative to the classical method, chemical antibacterial finishing process, towels with bamboo and silver yarn were obtained. The antibacterial properties of the yarns obtained with bamboo fiber are provided by the substance called Bamboo Kun in the structure of the fiber. An alternative has been created by using yarns obtained with bamboo fiber to provide antibacterial properties from the raw material. In the study conducted by Yüksek, it was observed that $60 \%$ bamboo- $40 \%$ cotton experiments did not show antibacterial activity, and they obtained antibacterial activity in the experiments with $70 \%$ bamboo- $30 \%$ cotton. Based on this result, experiments were made from $70 \%$ bamboo-30\% cotton yarns in this study [24]. Another alternative work is towels woven with yarn obtained using silver fiber. The main purpose of the study within the scope of antibacterial towel studies is to obtain antibacterial towels with antibacterial finishing chemicals, bamboo and silver thread. The antibacterial properties of the obtained towels were investigated.

\section{MATERIAL AND METHOD}

\subsection{Material}

Yarns made of $100 \%$ cotton, $70 \%$ bamboo - $30 \%$ cotton and $92 \%$ cotton - $8 \%$ silver fiber were used as materials in the study. Organofunctional silane-based antibacterial finish with a solid substance ratio of $4.12 \%$ was used to obtain antibacterial properties by chemical finishing method. In the study, the experiments were evaluated on the optical process without painting. Wetting agent, combined bleaching chemical, caustic (48 Beo), hydrogen peroxide $(50 \%)$, optical brightener, acetic acid $(80 \%)$, antiperoxide enzyme and softening chemicals were used for the optical treatment of the towels obtained. The companies from which the chemicals used are supplied are given in Table 1.

Table 1. Chemical supply companies

\begin{tabular}{cc}
\hline & Suppliers \\
\hline Wetting Agent & Denge Chemistry \\
Combined Bleaching Chemical & Rudolf \\
Caustic & Alde \\
Hydrogen Peroxide & Alde \\
Optical Brightener & NF Chemistry \\
Acetic Acid & Alde \\
Antiper Enzyme & Dystar \\
Softener & Rudolf \\
\hline
\end{tabular}

\subsection{Method}

\subsubsection{Yarn Production}

The properties of pile warp, ground warp and weft yarns used in the study are given in Table 2. The part that touches the human skin in the towel fabric is mainly the pile yarn. Therefore, the raw material to be used in the pile yarn should provide the performance expected from the towel and be suitable in terms of production. For this reason, cotton and bamboo raw materials are used in pile yarn. Yarns containing cotton, bamboo and silver fibers were used in the weft and ground warp threads. In the study, the 
effect of the fiber content in the yarn on antibacterial properties was investigated. In this context, vortex air-jet spinning system has been used as the spinning method for the production advantages of bamboo fiber, which is a regenerated cellulosic fiber.

\subsubsection{Towel Weaving Process}

In the study, the towels weaved by weft, ground warp and pile warp threads. The weaving process was carried out with a 3-weft method with two loops on both sides. Weaving processes were carried out on jacquard weaving machine (Dornier). The weaving processes were given in Table 3. The weft density in weaving operations was 19 pieces $/ \mathrm{cm}$ and the comb number was 11 teeth $/ \mathrm{cm}$.

\subsubsection{Wet Processes}

Optical whitening process was applied to the towel fabrics obtained within the scope of the study according to the exhaustion method in the MCS Model HT dyeing machine under the conditions given in Table 4. In this direction, optical treatment was applied to all experiments in the exhaustion method under the same process conditions. For the 4th experiment, antibacterial finishing process was applied as wet in the same process vessel in exhaustion method after standard optical treatment. As an antibacterial treatment, antibacterial treatment was performed with a solution containing $3 \%$ organofunctional silane-based antibacterial finish at $40{ }^{\circ} \mathrm{C}$ at a ratio of $1 / 7$ liquor for 30 minutes. Process parameters of the experiments performed are given in Figure 1 and Figure 2.

Table 2. Yarn information

\begin{tabular}{|c|c|c|c|c|}
\hline & Type Code & Yarn Count & Yarn Production Technique & Fiber Content \\
\hline \multirow{2}{*}{ Pile Warp Yarn } & $\mathrm{A}$ & $\mathrm{Ne} 14 / 1$ & Open End & $100 \%$ Cotton \\
\hline & B & $\mathrm{Ne} 14 / 1$ & Vortex & $70 \%$ Bamboo $-30 \%$ Cotton \\
\hline \multirow{2}{*}{ Ground Warp Yarn } & $\mathrm{C}$ & $\mathrm{Ne} 20 / 2$ & Open End & $\% 100$ Cotton \\
\hline & $\mathrm{D}$ & $\mathrm{Ne} 20 / 2$ & Vortex & $70 \%$ Bamboo $-30 \%$ Cotton \\
\hline \multirow{4}{*}{ Weft Thread } & A & $\mathrm{Ne} 14 / 1$ & Open End & $100 \%$ Cotton \\
\hline & E & $\mathrm{Ne} 16 / 1$ & Ring/Comped & $92 \%$ Cotton $-8 \%$ Silver Fiber \\
\hline & $\mathrm{F}$ & $\mathrm{Ne} 16 / 1$ & Vortex & $70 \%$ Bamboo $-30 \%$ Cotton \\
\hline & G & $\mathrm{Ne} 16 / 1$ & Ring/Carded & $100 \%$ Cotton \\
\hline
\end{tabular}

Table 3. Experimental parameters

\begin{tabular}{ccccc}
\hline Experimental No & Pile Warp Yarn & Ground Warp Yarn & Weft Thread & Fiber Content \\
\hline 1 & A & C & A + E & $98,4 \%$ Cotton $-1,6 \%$ Silver \\
2 & A & C & A + E & $99,2 \%$ Cotton $-0,8 \%$ Silver \\
3 & B & D & F & $70 \%$ Bamboo- $30 \%$ Cotton \\
4 & A & C & G & $100 \%$ Cotton \\
\hline
\end{tabular}

Table 4. Optical prescription

\begin{tabular}{cc}
\hline Chemical & Prescription \\
\hline Wetting Agent & $0,7 \mathrm{~g} / \mathrm{L}$ \\
$2 \mathrm{~g} / \mathrm{L}$ \\
Combined Bleaching Chemical & $4,5 \%$ (by the ratio of fabric weight) \\
Caustic & $11 \%$ (by the ratio of fabric weight) \\
Hydrogen Peroxide & $1,2 \mathrm{~g} / \mathrm{L}$ \\
Optical Brightener & $0,6 \mathrm{~g} / \mathrm{L}$ \\
Acetic Acid & $0,7 \%$ (by the ratio of fabric weight) \\
Antiper Enzyme & $1 \%$ (by the ratio of fabric weight) \\
Softener & $1 / 7$ \\
Flotte Ratio & \\
\hline
\end{tabular}

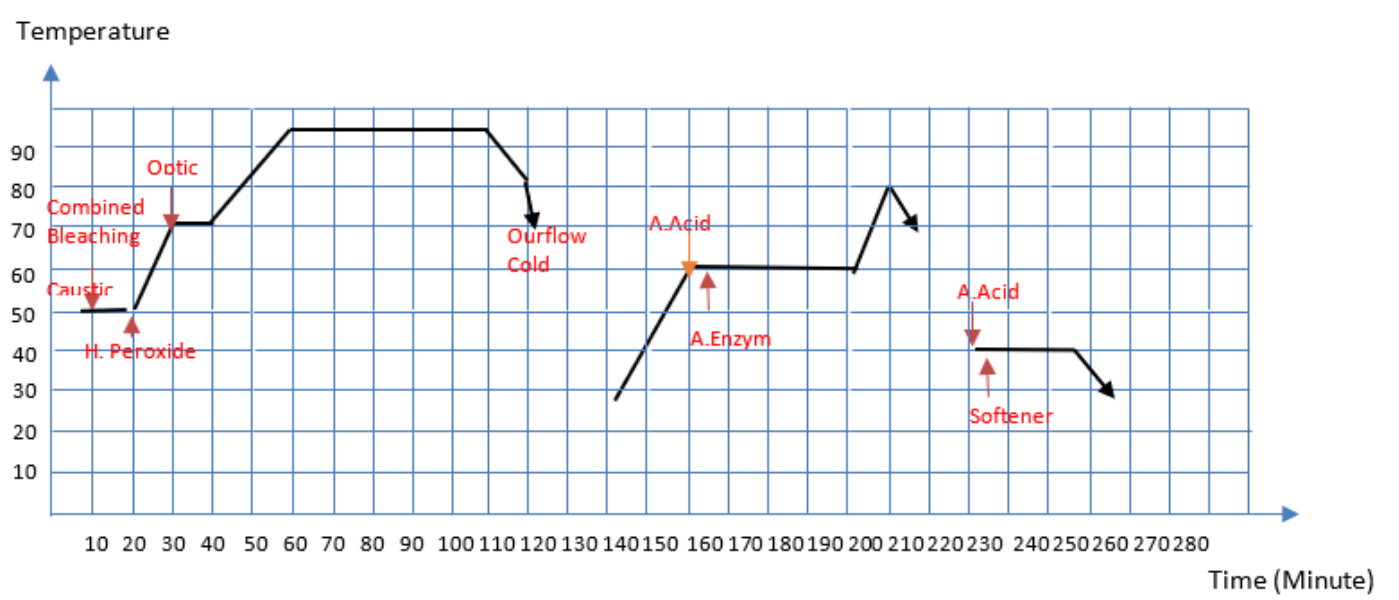

Figure 1. Standard optical connection 


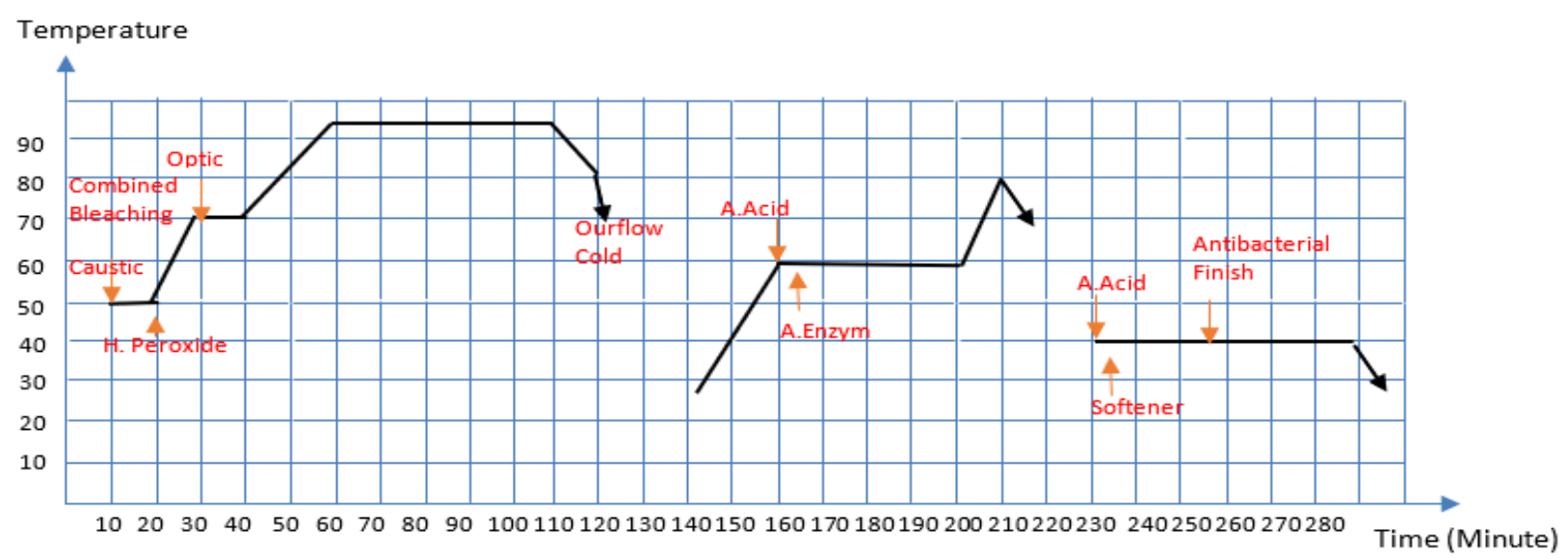

Figure 2. Optical and antibacterial treatment parameters for experiment 4

\subsection{Research Methods}

AATCC 100 antibacterial test method was applied to the samples to determine the antibacterial activity of the towel fabrics obtained. The tests were made with ATCC 6538 coded gram positive $S$. aureus bacteria and ATCC 4352 coded gram negative $K$. pneumoniae bacteria.

The hydrophilicity properties of the samples in the study were made in the TS 866 standard. In this study, the experiments were made with 7 repetitions and the average was taken. Images of the yarns used in terry fabrics were taken with the JVC C1380 color video CCD camera.

CIELab values of the samples in the study were measured using a spectrophotometer. Measurements were carried out using Color i7 brand spectrophotometer and x-rite software. All measurements were made under D65 daylight and using a $10^{\circ}$ observer angle. Through the software used, Berger, L
$*, \mathrm{a} *, \mathrm{~b} *$ values and color difference values were calculated with the CIELab 1976 formula.

\section{RESULTS AND DISCUSSION}

Different experiments were conducted within the scope of the study. Antibacterial efficacy performance and hydrophilicity results of the samples obtained were examined. Color differences were also detected. The microscope images of the yarns used in the study are given in Figure 3. Images of terry fabrics obtained from these yarns are given in Figure 4.

When Figure 3 is examined, the silver thread appears darker in the E-coded thread. Silver fiber is produced in ring spinning system together with cotton fiber. In the yarn, which has $8 \%$ silver fiber content, the silver fiber appears in the yarn structure as darker than cotton.
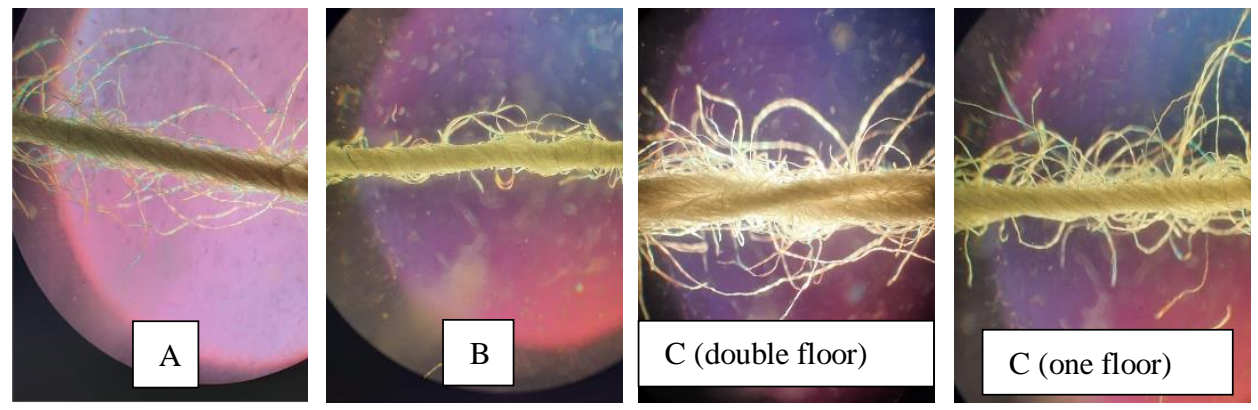

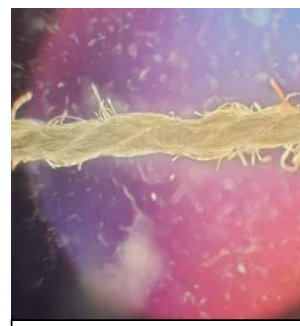

D (double floor)
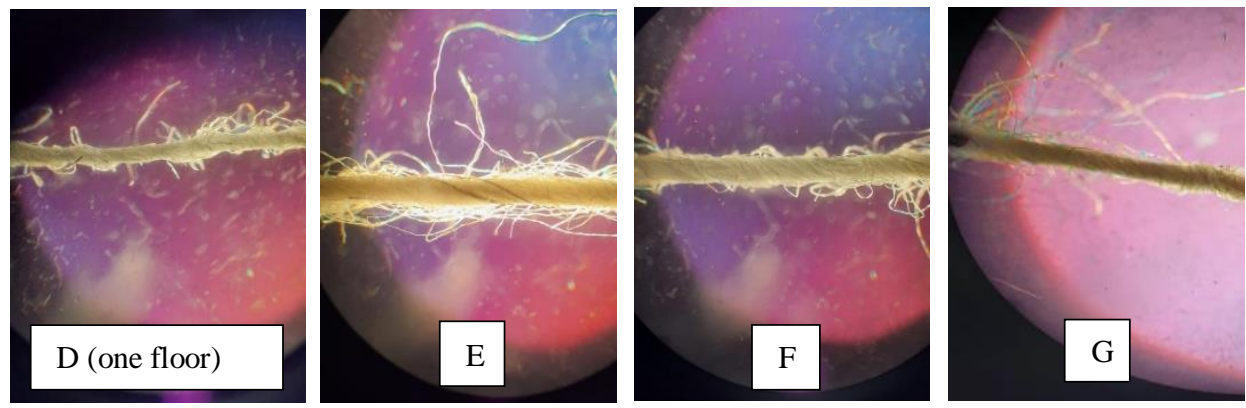

Figure 3. Images of experiment samples 


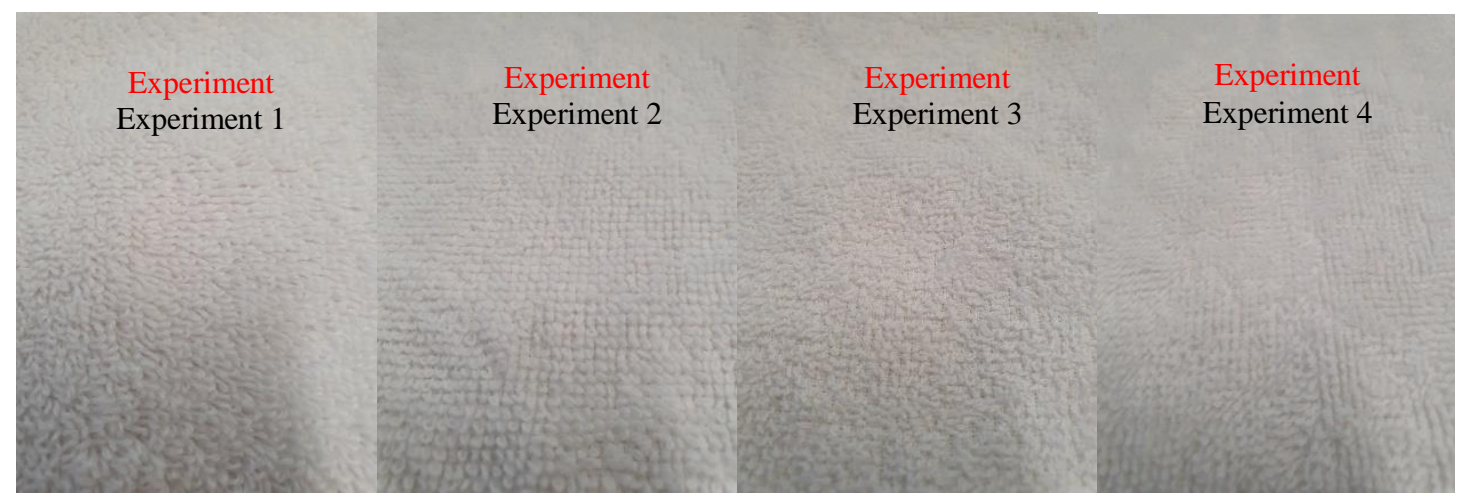

Figure 4. Images of experiment samples

\subsection{Antibacterial Test Results}

Two different types of bacteria were selected for the antibacterial activity test. Antibacterial test results of towel fabrics obtained as a result of the study are given in Figure 5.

When the antibacterial efficacy results of the study are examined, it is seen that all experiments show antibacterial efficacy close to each other. There are still new studies on silver-containing fibers and the subject remains up-to-date. In their study, Smiechowicz et al. (2020) conducted studies on obtaining antibacterial fibers containing nanosilica with immobilized silver nanoparticles. Antibacterial activity against S. Aureus and E. Coli bacteria was studied. As a result, fibers with antibacterial activity were obtained [25]. In their study, Xu et al (2017) coated the cotton fiber surface with silver and gained antibacterial properties. After 50 consecutive wash cycles in the study, bacterial reduction rates (BR) against both $\mathrm{S}$. aureus and $\mathrm{E}$. coli remained above 95\% [26]. The antibacterial activities obtained in the study gave similar results to the literature.

Sabir and Ünal (2017) examined the antibacterial activity of $100 \%$ cotton raw terry fabric within the experimental parameters by testing it in the AATCC 100 standard. When the results obtained from this study were examined, it was determined that the untreated (raw) 100\% cotton fabric did not show antibacterial activity [27]. When this study is taken as reference, it is seen that raw $100 \%$ cotton terry fabric has no antibacterial activity. However, high rates of antibacterial activity were obtained in the experiments conducted in the present study. Within the scope of the study, the antibacterial activity was investigated by evaluating the microorganism decrease in different periods ( 30 minutes, 2 hours, 4 hours, 6 hours, 12 hours and 24 hours) for the experiment using $0.8 \%$ silver yarn and the antibacterial chemical finishing experiment. Thus, the change of antibacterial activity depending on the time was determined. The data obtained are given in Figure 6 and Figure 7.

When Figure 5 and 6 are examined in the study, it is seen that the antibacterial activity increases with time. In the antibacterial efficacy test, it is expected that the microorganisms will decrease as the contact time of the samples that come into contact with microorganisms increases. The results confirm this. Bacteria increases between 30 minutes and 24 hours were $0.16 \%$ in $S$. aureus ATCC 6538 bacteria, $0.22 \%$ in K. pneumonie ATCC 4352 bacteria for Experimentl 2. Bacteria increases between 30 minutes and 24 hours were $0.15 \%$ in S. aureus ATCC 6538 bacteria, $0.19 \%$ in K. pneumonie ATCC 4352 bacteria for Experiment 4.

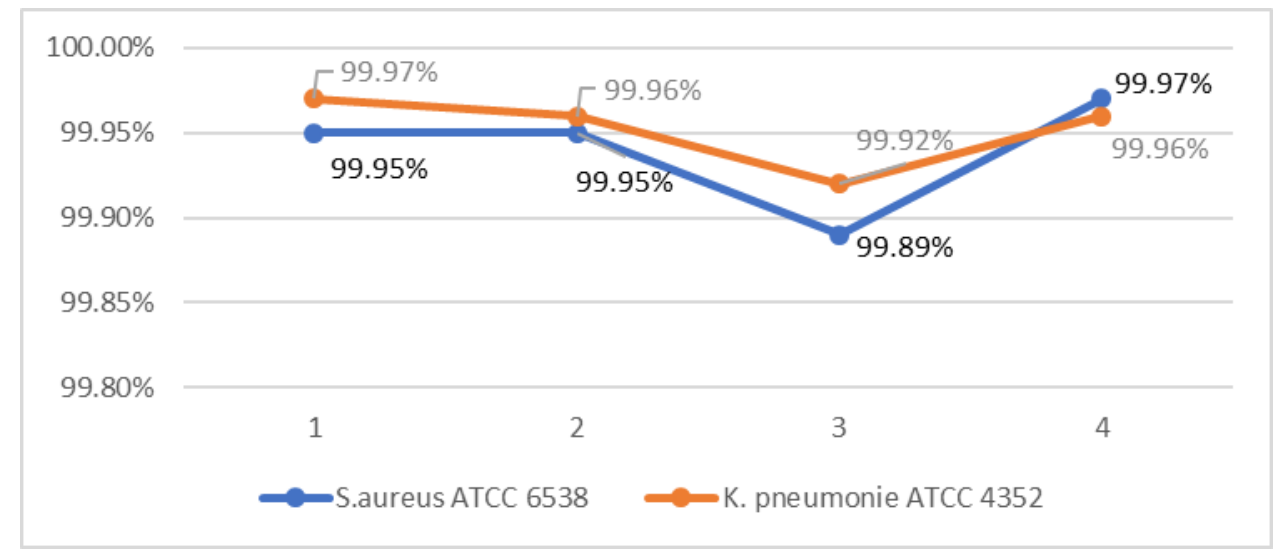

Figure 5. Antibacterial efficacy results (Reduction \%) 


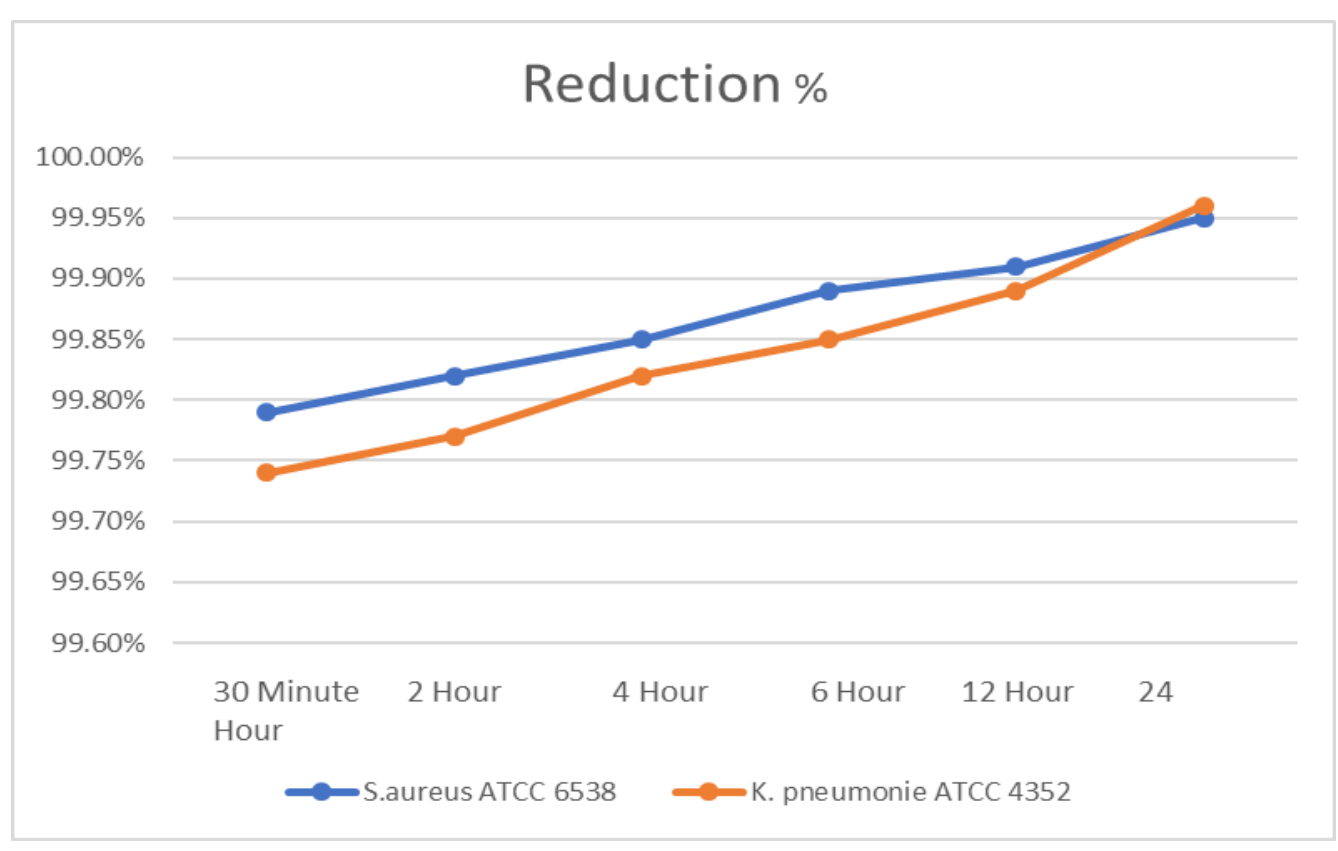

Figure 6. Antibacterial efficacy results for the experiment 2 sample (Reduction \%)

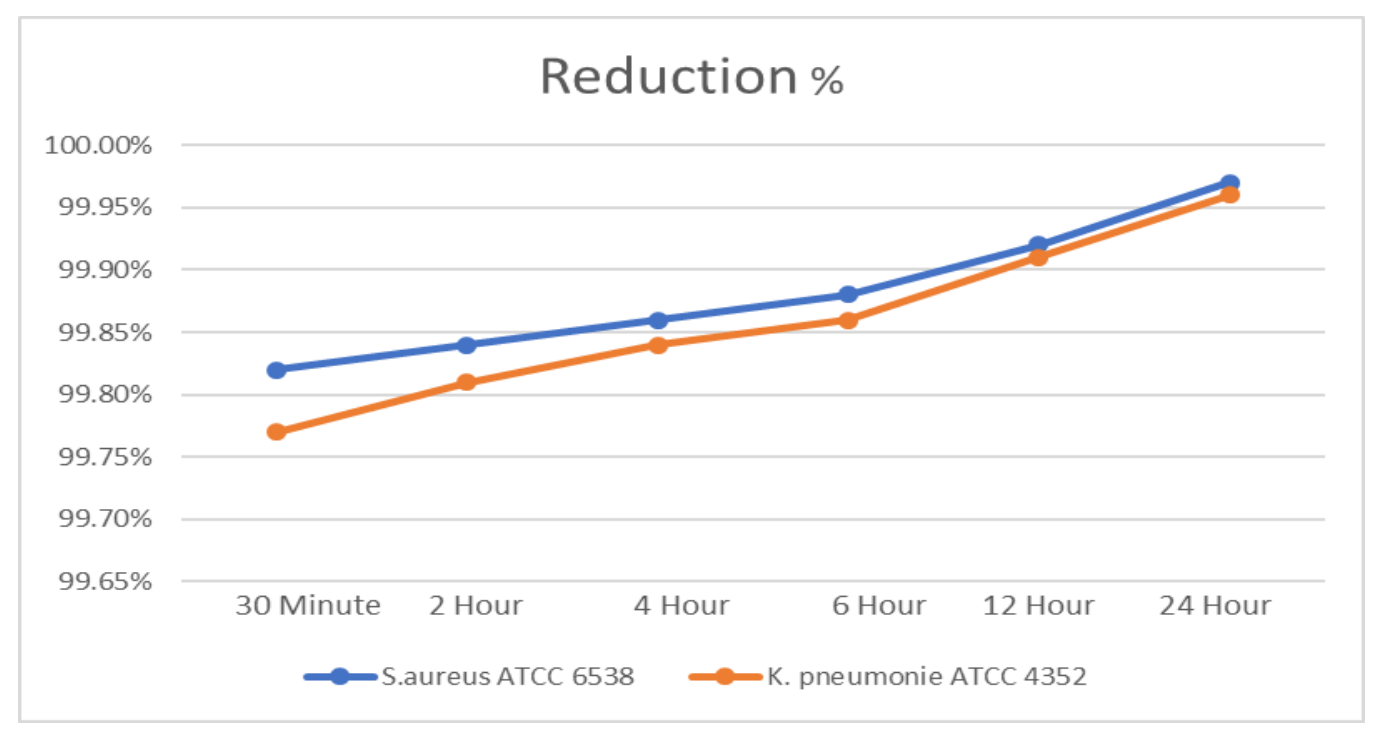

Figure 7. Antibacterial efficacy results for experiment 4 samples (Reduction \%)

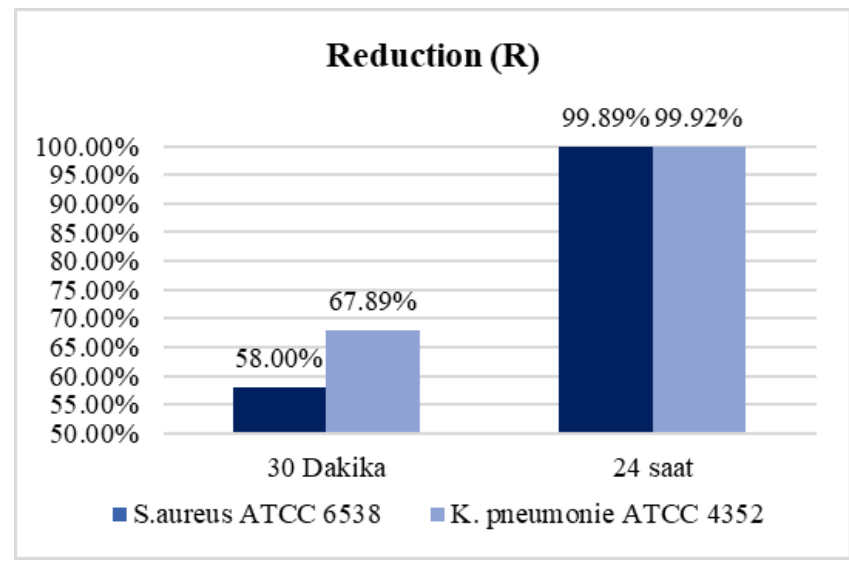

Figure 8. Antibacterial efficacy results for experiment 3 samples (Reduction \%)

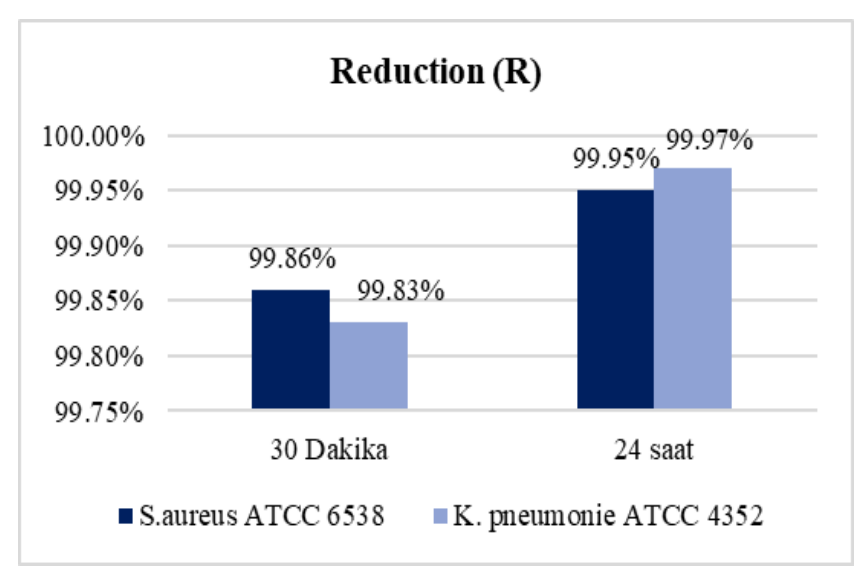

Figure 9. Antibacterial efficacy results for experiment 1 samples (Reduction \%) 
In Figure 7 and 8, the antibacterial activity increase for Experiment 3 and Experiment 1 is given. Microorganism reduction rate $(\%)$ was determined after 30 minutes and 24 hours in Experiment 3. When the results are examined, the reduction (R) \% values for 30 minutes were obtained as $58.00 \%$ in $S$. aureus ATCC 6538 bacteria and $K$. pneumonie ATCC 4352 bacteria $67.89 \%$ in K. pneumonie ATCC 4352 bacteria in Experiment 3. For 24 hours, the reduction (R) \% of S. aureus ATCC 6538 and K. pneumonie ATCC 4352 were $99.89 \%$ and $99.92 \%$, respectively in Experiment 3. When the amount of increase between 30 minutes and 24 hours was examined for Experiment 3, it was determined as $0.41 \%$ in $S$. aureus ATCC 6538 bacteria and $0.32 \%$ in $K$. pneumonie ATCC 4352 bacteria. For Experiment 1, the bacterial increase between 30 minutes and 24 hours was $11 \%$ in S. aureus ATCC 6538 bacteria and $14 \%$ in $K$. pneumonia ATCC 4352 bacteria.

\subsection{Hydrophilicity Test Results}

Hydrophilicity tests were conducted to determine the usability of the trial towels obtained within the scope of the study. Test results are given in Figure 10.

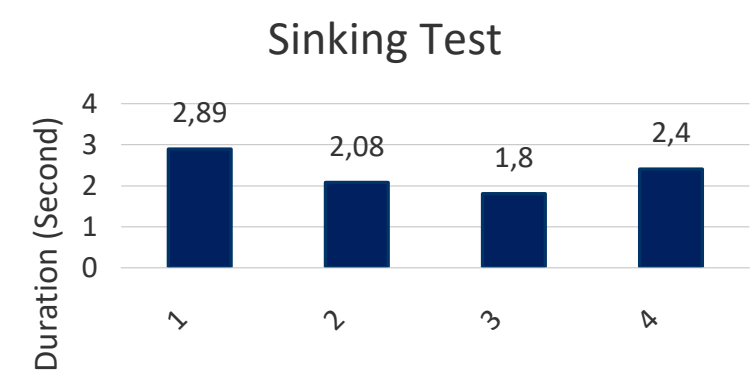

Figure 10. Sinking test results

The sinking test of the optic dyed towel without antibacterial chemical treatment was measured as 2.8 seconds. When the results are examined, it is seen that the hydrophility values of all of the experiments are close to the hydrophilicity value of the optic dyed towel sample without antibacterial treatment. Özmen (2010) stated in his master's thesis that the hydrophilicity value of the towel produced from bamboo fiber is better in the sinking test than the towel produced from cotton fiber [16]. In this study, it is seen that the sinking test value of the towels obtained with bamboo is lower.

\subsection{CIELab Results}

In the study, it is predicted that silver will create differences on the color due to its own color. For this reason, color differences were measured with reference to the chemical antibacterial finishing experiment. Berger values are given in Figure 11. $\mathrm{L} * \mathrm{a} * \mathrm{~b} *$ values of the reference are given in Table 5. Color difference results are given in Table 6.

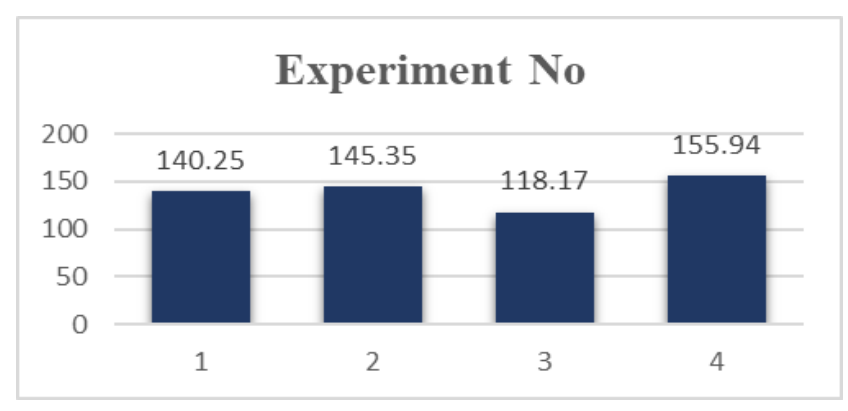

Figure 11. Berger values

Table 5. Reference $\mathrm{L} * \mathrm{a} * \mathrm{~b} *$ values

\begin{tabular}{cccc}
\hline $\begin{array}{c}\text { Experiment } \\
\text { No }\end{array}$ & $\mathrm{L}^{*}$ & $\mathrm{a}^{*}$ & $\mathrm{~b}^{*}$ \\
\hline 4 & 96,59 & 2,97 & $-11,96$ \\
\hline
\end{tabular}

Table 6. Results for CIELab color difference

\begin{tabular}{ccccccc}
\hline $\begin{array}{c}\text { Experiment } \\
\text { No }\end{array}$ & $\Delta \mathrm{L}^{*}$ & $\Delta \mathrm{a}^{*}$ & $\Delta \mathrm{b}^{*}$ & $\Delta \mathrm{C}^{*}$ & $\Delta \mathrm{H}^{*}$ & $\Delta \mathrm{E}$ \\
\hline 1 & $-3,44$ & 0,2 & 1,62 & $-1,51$ & 0,63 & 1,83 \\
2 & $-3,79$ & 0,81 & $-1,41$ & 1,57 & 0,42 & 1,84 \\
3 & 0,55 & $-0,36$ & 0,7 & $-0,77$ & $-0,19$ & 0,66 \\
\hline
\end{tabular}

In the color difference results, the desired limit values are expected to be below 1 in $\Delta \mathrm{E}$. When the color results are examined, it is seen that the color difference value of the Experiment 3 is within the desired limit values, while it is seen that there are color differences in the Experiments 1 and 2 due to the color of the silver itself. When Berger values are examined, it is seen that experiment 3 are lower than other studies.

\section{CONCLUSION}

Within the scope of the study, different methods were examined to obtain antibacterial towels. Antibacterial chemical finishing process is applied as the classical method for obtaining antibacterial towels. As an alternative to this method, bamboo fiber, which is widely used today, is also an alternative. However, it is supported by the literature that the rate of bamboo used in the towel has an effect on antibacterial activity. When all experiments are compared with antibacterial chemical finish, it is seen that the experiments performed as an alternative in the study show antibacterial efficacy. It has been observed that antibacterial activity does not change with $50 \%$ reduction in the use of silver fiber, and it is predicted that antibacterial effectiveness can be achieved by using lower amounts of silver. With the use of bamboo fiber and silver yarn in the towel fabric, antibacterial efficiency with high washing resistance can be achieved, while antibacterial activity with limited washing resistance will be achieved with chemical antibacterial finishing.

The classical method, antibacterial finishing application, has been carried out in experiments using silver and when 
the results are examined, it is seen that there is an increase in bacterial decreases depending on the time. In the experiments made from bamboo yarn, it is seen that the rate of bacterial reduction in 30 minutes is lower than other experiments.

\section{REFERENCES}

1. Çukul D. 2013. Examples for the recent developments in technical yarns. Journal of Textiles and Engineer 20(91), 50-63.

2. Beșen BS. 2019. Production of disposable antibacterial textiles via application of tea tree oil encapsulated into different wall materials. Fibers and Polymers 20(12), 2587-2593.

3. Abedi D, Mortazavi SM, Mehrizi MK, Feiz M. 2008. Antimicrobial properties of acrylic fabrics dyed with direct dye and a copper salt. Textile Research Journal 78, 311.

4. Gao Y, Cranston R. 2008. Recent advances in antimicrobial treatments of textiles. Textile Research Journal 78(1), 60-72.

5. Üreyen ME, Çavdar A, Koparalı AS, Doğan A. 2015. Antibacterial efficacy and laundering durability of textile fabrics treated by newly developed silver doped nano scaled bio-antimicrobial finishing agent. Journal of Textiles and Engineer 69, 26-31.

6. Ibrahim NA, Gouda M, Husseiny M, El-Gamal AR, Mahrous F 2008. UV-protecting and antibacterial finishing of cotton knits. Journal of Applied Polymer Science 112, 3589-3596.

7. Rimbu C, Cerempei A, Muresan R, Guguianu E, Ursache M, Borhan O, Muresan A. 2015. Eco-friendly antibacterial finish for natural knitted fabrics. Tekstil ve Konfeksiyon 25(4), 359-364.

8. Joshi M, Ali SW, Purwar R, Rajendran S. 2009. Ecofriendly antimicrobial finishing of textiles using bioactive agents based on natural products. Indian Journal of Fibre \&Textile Research 34, 295.

9. Filipowska B, Rybicki E, Walawska A, Matyjas-Zgondek E. 2011 New method for the antibacterial and antifungal modification of silver finished textiles. Fibres \& Textiles in Eastern Europe 19, 4 (87), 124-128.

10. Varesano A, Vineis C, Aluigi A, Rombaldoni F, Tonetti C, Mazzuchetti G. 2013. Antibacterial efficacy of polypyrrole in textile applications. Fibers and Polymers 14(1), 36-42.

11. Saengkiettiyut K, Rattanawaleedirojn P, Sangsuk S. 2008. A study on antimicrobial efficacy of nano silver containing textile. Special Issue on Nanotechnology 7(1), 33-36.

12. Dzhimak SS, Malyshko VV, Goryachko AI, Sokolov ME, Moiseev AV, Basov AA. 2019. Adsorption of silver nanoparticles on monoand polyfilament fibers. Nanotechnologies in Russia 14 Nos. 1-2, $48-54$.

13. Gülgönül M. 2018. Including silver complex production of nanofibers and use in textile, (Master's Thesis). Namık Kemal University Institute of Science.

14. Cruz J, Leitão A, Silveira D, Pichandi S, Pinto M, Fangueiro R. 2017 Study of moisture absorption characteristics of cotton terry towel fabrics. Procedia Engineering, 200, 389-398
It is predicted that alternative methods can be used in these trials to the antibacterial finishing application, which is used as the classical method.

15. Kakde MV, More H, Magarwadia B, Kejkar V. 2017. Effect of pile density on physical properties of terry towel fabric. International Journal on Textile Engineering and Processes 3(1).

16. Özmen B. 2010. Comparison of terryclothes which are made up with bamboo and cotton fiber in point of usag, (Master's Thesis). Gazi University Institute of Education Sciences.

17. Sekerden F. 2012. Effect of pile yarn type on absorbency, stiffness, and abrasion resistance of bamboo/cotton and cotton terry towels. Wood and Fiber Science 44(2), 189-195.

18. Erdumlu N, Ozipek B. 2008. Investigation of regenerated bamboo fibre and yarn characteristics. FIBRES \& TEXTILES in Eastern Europe 16, 4 (69), 43-47.

19. Mahish SS, Patra AK, Thakur R. 2012. Functional properties of bamboo/polyester blended knitted apparel fabrics. Indian Journal of Fibre \& Textile Research 37, 231-237.

20. Yasin S, Liu L, Yao J. 2013. Biosynthesis of silver nanoparticles by bamboo leaves extract and their antimicrobial activity. Journal of Fiber Bioengineering and Informatics 6(1), 77-84.

21. Tusief MQ, Amin N, Mahmood N, Ahmad I, Abbas M. 2015. Antimicrobial studies of knitted fabrics from bamboo, soybean and flax fibers at various blends. Journal of Textile Science \& Engineering 5(3).

22. Unango FJ, Ramasamy KM. 2019. A review on the investigation of biologically active natural compounds on cotton fabrics as an antibacterial textile finishing. International Research Journal of Science and Technology 1(1), 49-55.

23. Perelshtein I, Applerot G, Perkas N, Guibert G, Mikhailov S, Gedanken A. 2008. Sonochemical coating of silver nanoparticles on textile fabrics (nylon, polyester and cotton) and their antibacterial activity. Nanotechnology 19, 245705.

24. Yüksek İÖ. 2008. An investigation into the factors affecting the properties of bamboo yarns, (Master's Thesis). Uludağ University Institute of Education Sciences.

25. Smiechowicz E, Niekraszewicz B, Strzelinska M, Zielecka M. 2020. Antibacterial fibers containing nanosilica with immobilized silver nanoparticles. AUTEX Research Journal 20(4), 441-448.

26. Xu Q, Xie L, Diao H, Li F, Zhang Y, Fu F, Liu X. 2017. Antibacterial cotton fabric with enhanced durability prepared using silver nanoparticles and carboxymethyl chitosan. Carbohydrate Polymers 177, 187-193.

27. Sabır EC, Ünal BZ. 2017. The using of nettle fiber in towel production and investigation of the performance properties. Journal of Natural Fibers, 14(6), 781-787. 